ISSN-2199-353X

Online only at http://www.cahij.com/

\title{
ATLI BOZKIR KÜLTÜRÜNÜN JEOPOLITTİĞI UNSURLARINDAN KÜLTÜR
}

Kürşat KOÇAK*

\begin{abstract}
Özet
Jeopolitik bilimi modern bir kavram olmasına rağmen uygulama ve yöntemleri binlerce yıldır bilinmektedir. Bozkır Türk kavimleri bulundukları Avrasya coğrafyasından dolayı jeopolitik kuramlarını doğal olarak uygulamışlardır. Ancak bunun bilmeleri mümkün olmamıştır. Daha çok konargöçer atlı göçebe kültürünün etkisi ile jeopolitik üstünlük kazanmışlardır. Jeopolitikte en önemli unsurlardan biri coğrafya hâkimiyeti olmuştur. Bozkır Türk toplumu atlı göçebe kültürleri sebebi ile mobil bir hayat sürmüşler ve coğrafya hâkim olmuşlardır. $\mathrm{Bu}$ çalışmada jeopolitiğin kültür unsuru kısaca ele alınmıştır.
\end{abstract}

Anahtar Kelimeler: Türk, bozkır, jeopolitik, coğrafya.

\section{CULTURE FROM THE GEOPOLITICAL ELEMENTS OF MOUNTED STEPPE CULTURE}

\begin{abstract}
Science of jeopolitics has been known for thousands years, although it is seemed as a modern term. Steppe Turkish tribes used jeopolitic theories inherently because of geography of Eurasia. However, they didn't used it consciously. Their jeopolitic advantage depends on the effect of nomad on horseback. The geographical dominance is one of the significant element in jeopolitics. Steppe Turkish tribes lifestyle was mobile because of their nomadic cultures and gained the geographical advantage. In this work, the culture in jeopolitics is studied.
\end{abstract}

Keys Words:Turkısh, steppe, geopolitics, geography.

Giriş

Uzun tarihleri boyunca Türkler ilk olarak kendilerine ait özgün bir kültür oluşturmuşlardır. Aslında bu kültür günümüzdeki kültürün özünde mevcudiyetini korumaktadır ancak şekil olarak değişmiştir. Bu sebepten dolayı bugün büyük tehditler Türk kültürüne yöneltilmiştir. Türkler büyük devlet meydana getirirken kültürünü de meydana getirmişlerdir ve bu kültüre bu gün biz Bozkır Türk atlı kültürü demekteyiz. Bozkır kelimesi coğrafi bir terimdir. Bu kelime otlak ve çimenlerle kaplı alanları ifade eden bir tabirdir. Rusça "step" kelimesi "bozkır", "ot” ve "çimen” manasına kullanılmıştır. Söz konusu kelime batı dillerine "steppe" şeklinde geçmiştir. Türkçede de belirli bir süre "İstep" kelimesi kullanılmıştır. Günümüzde "step” yâda "istep” kelimesinin yerine Türkçede “bozkır” kelimesi

\footnotetext{
* Doç. Dr. Nevşehir Hacı Bektaş Veli Üniversitesi Fen-Edebiyat Fakültesi Tarih Bölümü Öğretim Üyesi. kocakkursat@nevsehir.edu.tr
} 
ISSN-2199-353X

\section{Online only at http://www.cahij.com/}

yaygın olarak kullanılmakta ve bu kelimenin otlakları, çimenlik ve çayırlık alanları ifade ettiği anlaşılmaktadır (Durmuş, Türk Kültürüne Giriş, 2016, s. 75). Bozkır coğrafyası yaylak ve kışlak hayatına imkân verecek şartlara sahiptir. Bu kapsamda kışlak ve yaylak önemli bir yer tutmaktadır. Mevsime bağlı farklılıklardan dolayı her yer yaşamak için uygun değildir. Zorunluluk olduğunda bahar ile güz mevsimi her yerde geçirilebilir. Çünkü baharda hayvanlar her yerde bol ot ve su bulabilirler, güzün dahi fazla yağış yüzünden taze ot biter. Buna karşılık, kışlak ve yaylak hayatı belirli şartlara bağlıdır. Bu şartlar oluşmadığı takdirde hayvan yetişmez. Kışlak için seçilen yer, hayvanları mevsimin sertliğinden korumalı, yani rüzgârdan korunmuş ormanlık veya derin bir vadi olmalı aynı zamanda bol su tutmalıdır. Buna karşılık, yayla için, göl ve akarsu boyları gibi, bol sulu, açık düz sahalar tercih edilir, hayvanların haşarattan daha az zarar görmeleri hususu da önemlidir (Durmuş, Türk Kültürüne Giriş, 2016, s. 76).

Türklerin teşkilatlanması ve alan hâkimiyetindeki en büyük güç etnik olarak tek bir milletten oluşmasıdır. Küçük karışmalara rağmen ana hâkim güç Türkler olmuştur. Bu Türk jeopolitiğinin itici gücünü Türk etnik menşeinin en eski zamanlardan beri üst üste yığılan katmanları olduğunu kabul etmemiz gerekir. Hun-Avar-Göktürk-Uygur-Karahan-SelçukluCengizli-Osmanlı vb. gibi sayısız siyasi yapıları üreten bu Türk etnik oluşumu, gerek bozkırı ve gerekse onu çevreleyen yerleşik medeniyetleri kendi yönetiminde birleştirecek yüksek idari kabiliyetlerini bozkır geleneklerinden almaktadır. Türk etnik oluşumu önce bozkırda ortaya çıkıp şekillenmiş ve oradan bozkırı çevreleyen yerleşik uygarlıklara hâkimiyetini genişletmiştir. Demir ve atla bütünleşmiş olan bozkırın atlı savaşçısı yaklaşık M.Ö. 1000 ile M.S. 1500 yılları arasında Mackinder'in ${ }^{1}$ merkez bölgesinden büyük askeri organizasyonlar düzenleyerek Hindistan, Çin, İran ve Avrupa tarihini şekillendirmişlerdir. Eski dünyanın bütün yerleşik mıntıkaları, er veya geç, bozkırın atlı savaşçısının yayılma gücüne boyun eğmiştir. Demir ve üzenginin sağladığı muazzam hareketlilik, eski dünya ölçeğinde kapalı bir sistem yaratmıştır. Tarih, 2500 yıldan daha fazla bozkır dünyası ile yerleşik dünya arasındaki diyalektik çelişki ekseninde yürümüştür (Gündoğdu, 2009, s. 84).

Tarihte ilk defa İnsanoğlu hareket kabiliyetini özellikle at ile elde etmiştir. İlim âleminde ciddi iddialara göre atı ehlileştiren veya en azından üzengiyi icat edip kullanan bozkır kültürü olmuştur. Atın ehlileştirilmesi insan hizmetine verilmesi tarihte büyük hamlelerden biri kabul edilmiştir. Adale kuvveti en fazla, tabii zorluklara en dayanıklı, değişik iklimlere tahammül bakımından en güçlü ve süratli hızda rakipsiz olan at, tarihi ve sosyal hayatta olduğu gibi din, edebiyat ve sanat alanında da büyük gelişmelere imkân sağlamıştır. Nitekim Türkler, ehlileştirdikleri at sayesinde ilk defa sürat kavramını fark etmiş, mesafeleri kısaltmış ve kazanılan zaman dolayısıyla derin bir zihniyet değişiklikleri yaşamış,

\footnotetext{
${ }^{1}$ Jeopolitik üzerine geliştirilen teoriler son iki yüz yıl içerisinde ortaya çıkmıştır ve içerisinde iki tanesi yaşama şansı bulmuş ve popüler olmuştur. Bunlardan birisi İngiliz, Halford John Mackinder'in (1861-1942) dünyayı merkez bölge, iç kenar ay bölgesi ve dış ay bölgesi olarak üçe ayırarak 1904 yılında yayınladığı, 1917 devriminden sonra Rusya'daki gelişmeleri dikkate alarak geliştirdiği ve "Demokratik İdealler ve Gerçek" isimli kitabında, "Kara Hâkimiyet (Kalpgâh) Teorisi” olarak açıkladığı görüşlerdir (İlhan, 2019, s. 29).
} 
ISSN-2199-353X

\section{Online only at http://www.cahij.com/}

maharet ve cesaret gerektiren at binme işini kendisiyle özdeş hale getirerek yayalar üzerinde mütemadiyen hâkimiyetler tesis etmiştir. Bu bağlamda at'a sahip olma; ülke nüfus, İdari bakımdan dar sınırlardaki kapalı Türk boylarına Göktürkler, Uygurlar, Avarlar gibi devletler geniş imparatorluklar kurma şartları hazırlamıştır (Ahmetbeyoğlu, 2016, s. 42).

İskitlerin yayıldığı coğrafya hakkında bilgileri, hem yazılı kaynaklarda hem arkeolojik kaynaklardan öğrenebilmekteyiz. Yazılı kaynaklarda İskitler ya giyinişlerine ya da bulundukları coğrafyaya göre adlandırılmıştır. İskitlerin M.Ö. I. bin yıl içinde Tuna Nehri'nden başlayarak doğuda Çin'in batı sınırlarına kadar uzanan oldukça geniş bir sahaya yayıldıklarını arkeolojik buluntular göstermektedir. Kuzeydoğu bozkır bölgesi Pamir, Altay, Tanrı Dağlarından Batı Türkistan üzerinden batıya ve aşağı Tuna bölgesine kadar, Güney Rusya’ya yayılmaktadır. Doğuda Doğu Türkistan ve Gobi çölüne kadar ulaşmaktadır doğu kısmı büyük çöl sahasıyla kaplı olmasına rağmen batı kısmı genellikle verimli ve tarıma elverişlidir. Kuzey kısmı ise bataklıklar ve sık ormanlıklarla kaplıdır. Doğu ve güneyde Hazar Denizi ve Karadeniz, geri kalan kısımlar İran'daki dağlık arazinin yükselen dağ dalgaları ve Kafkas dağ silsilesiyle sınırlanmıştır. Bölgenin sınırları Antik Çağda doğudan batıya doğru Nanşan ve Tanrı Dağları ile Oxus Nehri'nden (Ceyhun Nehri) oluşmaktaydı (Selçuk, 2019, s. 28). Bozkır kültürünü batıya ilk taşıyanlar İskitler olmuştur. İskitler Bozkır atlı kültürü ile atı ve Türkistan sanatını beraberlerinde taşımışlardır. Avrupa'nın ilk çağlarda şekillenmesine yol açan Bozkır Türk boylarının öncüsü olmuşlardır.

Türklerin tarihte ortaya çıktığı devirlerde yaşayan pek çok kavim ve boy günümüzde mevcut değildir. Türklerin günümüze kadar güçlü bir şekilde yaşamasının esas temeli ise kültürüdür. Kültür bireysel olmayıp sosyal değerler ve davranışlar sistemi yani başlı başına bir hayat tarzıdır. Kültür, insanın fizyolojik ve içgüdüsel hayatıyla ilgili olmayan süper-organik bir olaydır. Kültür, sosyal bir mirastır ve genç kuşaklara öğrenme ve şartlanma yoluyla geçer, böyle bir oluşum da ortak bir dilin varlığ 1 ile mümkündür. Kültür, bir birikim olarak ait olduğu toplumun geleceğini muhafaza etmek için kendi normlarını korumak zorundadır. Kültür bir toplumun bütün ideallerinin ve sosyal kişiliğinin sembolüdür. Her toplum, kültürünü oluşturan bu idealleri gerçekleştirmeye çalışır. Kültürel değerlerin muhafazası ne kadar hayati bir öneme sahipse, kültürde değişme olgusu da önemlidir. Başka bir ifadeyle, kültürel değerler dogmatik olmayıp çağın ihtiyaçlarına göre değişmek zorundadır (Yuvalı \& Yoska, 2019, s. 34).

İslamiyet öncesine rastlayan Türk Tarihi Birinci Jeopolitik Dönemi kültürü, “Atlı Bozkır Türk Kültürü” olarak isimlendirilmiştir. Bu kültür, Türk tarihinin göç ve savaş özellikleri ile şekillenmiş, aynı zamanda bu özellikleri desteklemiş ve yönlendirmiştir. Atlı Bozkır Kültürünün en önemli ve en etkili olan "Benimsenen Temel Düşünce Sistemi”ni Gök Tanrı (Tek Tanrı), Şamanizm ve Türk töresi inanç sistemi oluşturur. Gök Tanrı inancı dünyanın oluşunu açıklar, evrensel ve Tanrısal gücü belirler; Şamanizm insan ve ruhlar arasındaki ilişkileri açıklar, bir bakıma düzenler, hastalar için çözüm arar; töre ise dünyevi (aynı zamanda beşeri) işleri ve ilişkileri düzenler. Türklerin inandıkları Tanrı, Orhun 
ISSN-2199-353X

Online only at http://www.cahij.com/

Kitabesinde açıklandığı gibi Türk Tanrısıdır. Gök Tanrı inancının Yalvaçı, Türk kozmogoni ve hikmetini üreten Türk akıl ve sezgisidir; Türk ortak aklıdır (İlhan, 2019, s. 120).

Bozkır Atlı Kültürü Jeopolitik unsurları ise "halk, ülke, hâkimiyet ve teşkilattan" meydana gelmekteydi. Bu unsurlar aynı zamanda Bozkır devlet mekanizmasının dörtlü saç ayağını meydana getiriyordu. Türkler devlete "él" veya "il" adını veriyorlardı. Devlet kurmay1 "illemek", devlet idare etmeyi "İl tutmak", devleti düzene sokmay1 "İl itmek", devletten yoksun kalmaya da "İlsirmek" kelimeleriyle ifade ediyorlardı. Devleti de, daima "töre" ile birlikte düşünüyorlardı. Başka bir ifade ile söylemek gerekirse, Türklerde töresiz (Töre= yazılı olmayan kanun) devlet olmamaktaydı (Koca, Türk Kültürünün Temelleri II, 2010, s. 66). Bu unsurların en temel taşıyıcısı ise töredir. Türk töresi, toplumun bütün kesimlerinin Kağan da dâhil olmak üzere herkesin uyması gereken hukuk kuralları toplamıdır. Devletin ve kağanın iktidarının sürekliliği için hukuk kurallarının korunması ve ona riayet edilmesi büyük önem taşıyordu. Töresini kaybeden bir millet yok sayılacağı için devletten bile önce töre gelmekteydi (Selçuk, 2019, s. 58). Jeopolitiğin ana unsuru kültürdür. Bozkır atlı medeniyetinin ana unsuru kültürdür. Güç odağı unsuru için de etkili bir öğedir. Güç odakları; tek devlet de olsa birçok üyenin oluşturduğu uluslararası birlik olsa, ortak kültür unsurlarına sahip güçlü bir kültür çevresine sahip olmalıdır. Güçlü kültür çevresi; güçlü bir güç odağ1 oluşmasının vazgeçilmez koşuludur (İlhan, 2019, s. 23). Sosyal bilimlerde kültür denilince, bir topluluğun kendi, hayati problemlerini çözmek üzere denediği ve uzun yıllar içinde standart hale getirdiği usuller ve vasıtalar anlaşılır. Şu halde bir topluluğun ihtiyaçlarını karşılamak üzere benimsemiş bulunduğu hayat tarzı, bütün maddi ve manevi unsurlarıyla birlikte onun kültürünü teşkil etmekteydi (Güngör, 1996, s. 68).

Kültür; bir toplumun sahip olduğu dil, din, gelenek, sanat ve hayat tarzı gibi unsurların bir bütünüdür. Bir başka deyişle, bir milletin tarihi boyunca meydana maddî ve manevî değerlerin bütünüdür (Koca, Türk Kültürünün Temelleri II, 2010, s. 11). Kültür kelimesinin çeşitli manaları vardır. Aslında Latincede "toprağı işleme” demek olan bu tabir, sonraları Batı Avrupa dillerinde kazandığı "yüksek umûmî bilgi” manası ile Türkçe’ye de girmiştir. Kültür sözü biraz daha hususileştirilerek şu tabirlerde de kullanılmaktadır: İptidai kültür, ileri kültür, beşerî kültür, teknik kültür, yerleşik kültür, aşiret kültürü, kültür kavimleri-tabiat kavimleri vb... (Kafesoğlu, Türk Milli Kültürü, 1997, s. 14)

Dünyada Türkler kadar eski bir tarihe sahip olan pek az millet gösterilebilir. Bu kadar uzun macerası olan bir millet hâlâ yaşadığına göre ve yakın zamana kadar dünyanın en büyük imparatorluğunu yaşattığına göre, her şeyden önce eşi az görülür bir hayat gücüne sahip demektir. Türk milleti şimdiye kadar hiç esir olmamış, üstelik bugün Birleşmiş Milletler Teşkilâtının millet sıfatını verdiği birçok toplulukları idaresi altında tutmuştur. Şu halde yüzlerce yıl içinde teşekkül etmiş olan Türk kültürü bu milleti başkalarına hâkim kılacak kadar da güçlü idi (Güngör, 1996, s. 69). 
ISSN-2199-353X

\section{Online only at http://www.cahij.com/}

$\mathrm{Bu}$ bağlamda Türk devletleri kültür unsuruna dayanarak kurulmuştur. İskitlerin Türklüğü hakkında en somut veriler kültür unsurlarıdır. Bu konudaki en değerli bilgileri bize Herodotos vermiştir. Herodotos $=4$. Kitap "Melpomene" İskitler hakkında ciddi derecede bilgi vermektedir. Halikarnaslı Herodotos (MÖ 484 - 425) eserinde değişik yerlerde Pers Yunan Savaşı hakkında bilgi vermektedir. Özellikle 4. kitabında ise İskitlerin coğrafyası, sınırlarının oluşumu, adetleri, dinleri hakkında bilgi vermektedir. Herodotos İskitlerin yurtları, genel özellikleri, gelenekleri, kültürleri hakkında bilgi vermektedir. Jeopolitiğin en önemli unsuru tarihtir. Tarihinde antikçağda bilinen ilk siması Herodotostur. Herodotos bugün dahi tartışmaları devam eden İskitlerin kökeni meselesinde ilk görüşü öne sürmüştür ve ona göre İskitler Asya kökenlidir. "İskitler Asya'dadırlar, Massagetlerle yaptıkları bir savaştan yenik çıktılar, Araxes ırmă̆gnı geçtiler, Kimmerlerin yanına göç ettiler.” (Herodotos, 2006, s. 298). Herodotos İskit günlük yaşamı adetlerini yazmayı ihmal etmemiştir. İskitlerin gelenek ve göreneklerine dair bilgileri Herodotos ve Hippokrates'ten öğrenmekteyiz. Herodotos ve Hippokrates İskitlerin hayat tarzı ve bazı âdetleri hakkında önemli bilgiler vermektedir. Herodotos İskitlerin gelenek ve göreneklerine bağlı ve yabancı geleneklere kesinlikle kapalı bir toplum olduğunu belirtmektedir. Hippokrates ise İskitlerin göçebe bir kavim olduğunu, onların soğuğa karşı korunaklı keçeyle kaplı, dört ya da altı tekerli, öküzler tarafından çekilen arabalarda yaşadıklarını hayvanlarına otu bol otlaklar bulmak için dolaştıklarını belirttikten sonra onların pişmiş et yediklerini ve kısrak sütü içtiklerini bildirmektedir (Durmuş, İskitler, 2008, s. 24).

Herodot'un verdiği bilgilerde İskitlerin Türklüğüne dair açık işaretler vardır. Başlıca, Papaeus (Gök Tanrı), Apia (Yer Tanrısı) ve Tabiti (Ev ve Aile Tanrısı) olmak üzere üç tanrı bulunmaktadır. Eski Türklere ait bütün eski kaynaklar Gök Tanrı (Tengri) ile Yer Tanrısı (Yersub)'nın varlığından bahsediyor. Bu iki Tanrı'dan başka, Türklerde bir de Umay adında ev hayatına ve çocuklara bakan bir Tanrıça bulunmaktaydı. İskitlerin Tabiti adını verdikleri tanrıça fonksiyonu itibarıyla eski Türklerdeki Umay'a tekabül etmektedir (Durmuş, İskitler, 2008, s. 22). Herodotos hükümdarları öldüğü zaman, İskitler tarafından o bölgede eni boyu bir dörtgen, büyük bir mezar kazıldığını ve ölünün mumyalandığını belirttikten sonra hayatta olanların kulak memelerini kestiklerini, başlarını çepeçevre kazıdıklarını, kollarını çizdiklerini, alınlarını ve burunlarını yırttıklarını bildirmektedir (Herodotos, 2006, s. 322; Durmuş, İskitler, 2008, s. 26).

İskitlerde atalar saygıyla yad ediliyordu. Onların hayatında atalarının mezarlarının önemli bir yeri vardı. Bir ölçüde onları yurtlarına bağlayan en önemli unsurlardandı. Bunu Darius'un İskitler üzerine yapmış olduğu sefer sırasında çok iyi anlıyoruz. Darius İskit Hükümdarına elçi göndererek kendisine karşı koyabilecek gücü varsa karşısına çıkarak savaşmasını ister. İskit hükümdarı ise hiç kimseden korkmadığını, hiçbir kentleri ve dikili ağaçlarının olmamasından dolayı savaşa girmediğini belirtir. Ancak, Persler atalarının mezarlarını bulup onlara zarar verirlerse o zaman savaşacaklarını bildirir (Durmuş, İskitler, 2008, s. 23). 
ISSN-2199-353X

\section{Online only at http://www.cahij.com/}

İskitler arasında oldukça fazla olan falcılar kehanetlerinin icrasında söğüt çubukları kullanmışlardır. Bu kehanet gösterme tarzı da günümüzde bile çok sayıda gayrimüslim Türk'ün dini merasimlerde çubuk kullandıkları düşünülecek olursa İskitlerin Türklüklerinin bir delili olarak düşünülebilir. Herodotos, İskitlerin nasıl ant içtikleri hakkında da bilgi vermektedir. $\mathrm{O}$, ant içenlerin toprak bir kabın içerisine şarap doldurup, kanlarını bunun içerisine karıştırdıktan sonra içtiklerini ve orada bulunan ileri gelen kişilere de ikramda bulunulduğunu belirtmektedir. İskitlerdeki bu merasim de eski Türklerde görülen ant içme merasiminin aynıdır. Bu merasim Asya Hunlarında da aynı şekilde yapılmaktadır. Hun hükümdarlarından Hu-han-ye MÖ I. yüzyılın ortalarında Çin elçileriyle anlaşma yaptığı zaman şaraba kan karıştırarak içmiştir. Bunun Ural-Altay kavmi olarak Macarlar ve Kumanlar arasında da yaygın olduğu bilinmektedir (Herodotos, 2006, s. 322; Durmuş, İskitler, 2008, s. 25)

Milat'tan evvel ilk defa M.Ö. 10. Yüzyıl civarında ilk defa doğudan batıya Bozkır insanı göçe başlamıştır. Moğolistan civarından Orta Avrupa'ya kadar sürecek göçler dizgin ve koşum ile mümkün olmuş ve dünya tarihinde ilk defa küreselleşme hareketleri başlamıştır. Doğudan başlayan göçlerin taze su ve otlak bulmak amaçlardan biri olduğu düşünülmektedir. Bozkır göçerleri Hazar Denizi'nin kuzeyinden geçip Karadeniz'in Kuzeyine gelmişler ve burada İskitler başta olmak üzere diğer boylar burada hâkimiyet sahası tesis edip devletler kurmuşlardır.

Bozkır Türk devletlerinin kuruluşuna giden yolda önemli vasitalardan biri de at olmuştur. Çünkü Bozkır Türk devletleri at üzerinde kurulmuştur. Atın ehlileştirilmesi ve atl1çoban kültürünün ortaya çıkmasıyla birlikte insanlık tarihinde ulaşılan bu başarı, kavimlerin ve diğer kültürlerin gelişmesinde fevkalade sonuçlar doğurmuştur. Tarihî bağlantıların gösterdiği gibi, büyük devlet esası için gerekli şartlar bu sayede belirebilmiştir. M.Ö. II. Bin yılın başlarında atın etkin olarak binek hayvanı olarak kullanılmasıyla hareketli hayat tarzı geniş coğrafyalara kısa zamanda yayılmaya başlamıştır (Durmuş, "Eski Türk Devletlerinin Oluşumun Temel Unsurları”, 2008, s. 26)

\section{Sonuç}

Sonuç olarak jeopolitikte coğrafya ve kültürel üstünlük önemlidir. Bozkır atlı göçebe kültürü gereği taze ot ve su bulmak için coğrafyayı çok iyi tanımayı gerektirmiş vede tanımışlardır. $\mathrm{Bu}$ durumun avantajını kullanarak tarihin en güçlü devletlerini kurmuşlardır. Coğrafyaya hâkimiyetlerini dünya hâkimiyeti stratejileri ile pekiştirmişlerdir. Bununla alakalı olarak bozkırın kendine has kültürü lokomotif güç olmuştur. Bu kültürden kaynaklı olarak da bozkır jeopolitiğinin kültür unsuru meydana gelmiştir.

\section{KAYNAKÇA}

Ahmetbeyoğlu, A. (2016). Atlı Şehirliler( Buluntular ve Kalemin Dilinden Avrupa'da Hun Kültürü). İstanbul: Yeditepe Yayınları. 
ISSN-2199-353X

Online only at http://www.cahij.com/

Durmuş, İ. (2008). "Eski Türk Devletlerinin Oluşumun Temel Unsurları”. Gazi Türkiyat, Sayı $2,25-45$.

Durmuş, İ. (2008). İskitler. Ankara: Genelkurmay Yayınevi.

Durmuş, İ. (2016). Türk Kültürüne Giriş. Ankara: Akçağ Yayınevi.

Gündoğdu, A. (2009). Türk Jeopolitiği. İstanbul: IQ Kültür Sanat Yayıncılık.

Güngör, E. (1996). Türk Kültürü ve Milliyetçilik. İstanbul: Ötüken Neşriyat.

Herodotos. (2006). Tarih. Terc. Mümtekin ÖKMEN. İstanbul: İş Bankası Yayınları.

İlhan, S. (2019). Jeopolitik (Güç Odă̆ı Kuramı). İstanbul: Kırmızı Kedi Yayınevi.

Kafesoğlu, İ. (1997). Türk Milli Kültürü. İstanbul: Ötüken Neşriyat.

Kafesoğlu, İ. (1997). Türk Milli Kültürü. İstanbul: Ötüken Neşriyat.

Koca, S. (2000). Türk Kültürünün Temelleri II. Ankara.

Koca, S. (2010). Türk Kültürünün Temelleri II. Ankara: Pelin Ofset.

Selçuk, H. (2019). Selenge'den Tuna'ya Türk Kültür Tarihine Dair Notlar. İstanbul: Kitaparası Yayınları.

Yuvalı, A., \& Yoska, E. (2019). Türk Dünyasının Ortak Kültürel Değerleri. Konya: Kömen Yayınları. 